\title{
PROTOTYPE KARTU PINTAR KAMAR TIDUR MENGGUNAKAN SENSOR INFRARED DAN PHOTODIODA BERBASIS ARDUINO UNO
}

\author{
Ikhsan Parinduri \\ Program Studi Sistem Komputer, STMIK Royal Kisaran, \\ STMIK Royal Kisaran, J1. M.H.Yamin No.179 Kisaran, \\ ikhsanparinduri9@gmail.com
}

\begin{abstract}
Abstrak - Kartu pintar (Smart Card), secara fisik, adalah kartu plastik seukuran kartu kredit yang dapat diisi dengan datauntuk berbagai keperluan. Sejumlah pemanfaatan kartu pintar antara lain adalah pembayaran tunai secara elektronis, sistem presensi, kartu berlangganan tiket kereta api dan bus, pembayaran jalan tol, dan lain-lain. Perancangan Kartu pintar untuk kamar tidur dengan menggunakan sensor photodioda dan sensor infrared berbasis Arduino Uno telah berhasil dengan baik sesuai prosedur.Sistem Kerja dari rangkaian kartu pintar kamar tidur sangat bermanfaat untuk efisiensi penggunaan listik di rumah tangga.Sistem kerja dari sensor photodioda dan sensor infrared sangat baik dalam perangkaian yang berfungsi sebagai sensor cahaya
\end{abstract}

Kata Kunci - Kartu Pintar, Arduino Uno

Abstract - Smart card (Smart Card), physically, is a plastic card the size of a credit card that can be filled with datafor various purposes. A number of smart card utilization include electronic payment of cash, attendance system, train and bus ticket subscription card, toll road payment, and others. The design of smart card for bedroom using photodioda sensor and infrared sensor based on Arduino Uno has succeeded well according to procedure. Working system from smart card chamber circuit is very useful for efficiency of household electrical use. Either in a series that serves as a light sensor

Keywords - Smart Card, Arduino Uno

\section{PENDAHULUAN}

Pada masa saat ini konsumsi dalam penggunaan listrik dimasyarakat sangat tidak stabil, baik itu dalam konsumsi listrik rumah tangga maupun perkembangan dunia industri. Dalam konsumsi listik rumah tangga kita bisa lihat realitanya adalah dalam alat-alat rumah tangga misalnya dispenser (pemanas air), magic com (pemanas nasi), kulkas dan lain-lain, penggunaaan listrik untuk ruangan makan, ruangan tempat tidur hingga ruangan kamar mandi.

Konsumsi listrik khususnya sangat di efisienkan dalam penggunaannya, dikarenakan keterbatasan untuk sumberdaya alam dalam pengolahan untuk menghasilkan listik tersebut. Banyak penelitian saat sekarang ini untuk 
efisiensi penggunaan listrik dengan alat yang digunakan secara otomatis dalam penggunaanya diantaranya adalah menggunakan kartu pintar (Smart Card).

Kartu pintar (Smart Card), secara fisik, adalah kartu plastik seukuran kartu kredit yang dapat diisi dengan datauntuk berbagai keperluan. Sejumlah pemanfaatan kartu pintar antara lain adalah pembayaran tunai secara elektronis, sistem presensi, kartu berlangganan tiket kereta api dan bus, pembayaran jalan tol, dan lain-lain.

Penelitian tentang Smart Card yang mendukung diantaranya adalah Santosa, 2010, Prototipe Kantin Tanpa Uang Berbasis kartu pintar "sebuah prototipe aplikasi desktop yang memanfaatkan kartu pintar untuk mode pembayaran transaksi tanpa uang tunai pada sebuah kantin. Kartu pintar, selain digunakan untuk autentifikasi, juga dirancang memiliki informasi saldo uang dan sedikit data pribadi pemegang kartu.

Penelitian puasandi,2014, Sistem Akses Kontrol Kunci Elektrik Menggunakan Pembacaan eKTP, e-KTP termasuk dalam jenis Smart Card yang dimanfaatkan sebagai angkutan public transit, layanan kesehatan, passport, token akses. Dirancang sebuah sistem kunci elektrik dengan memanfaatkan NFC sebagai reader e-KTP dengan frekuensi kerja 13.56 MHz. Kunci elektrik dilengkapi dengan modul database yang terhubung secara wireless UART. Database berfungsi untuk menyimpan unique ID dari e-KTP dan logger presensi masuk ruang.

Penelitian wildian,2010, Rancang Bangun Prototype Sistem Kontrol Pintu Berbasis Mikrokontroler AT89S51 Menggunakan Kartu Ber-Password dan sensor Fotodioda "Kartu ber-password ini dibuat dari kartu ATM bekas yang diberi lubang dengan jumlah, posisi dan jarak tertentu. Dengan menggunakan sistem sensor yang terdiri dari 8 pasang LED-fotodioda (jarak deteksi antara 4,7 cm hingga 5,2 cm), maka kartu ber-password yang disisipkan diantara LED dan fotodioda itu memiliki kode password 8-bit sesuai posisi dan jumlah lubang. Bagian kartu yang berlubang akan menyebabkan keluaran fotodioda low (antara $0 \mathrm{~V}$ hingga 1,5V), sedangkan bagian yang tak berlubang akan menyebabkan keluaran fotodioda high (antara 4V hingga $4,5 \mathrm{~V})$.

Dari uraian tersebut diatas, maka judul penelitian dalam tugas akhir ini adalah "Prototype Kartu Pintar Kamar Tidur Menggunakan Sensor Infrared dan Photodioda Berbasis Arduino Uno.

\section{METODE PENELITIAN}

Alat yang akan dirancang dalam penelitian ini adalah Prototype Kartu Pintar Kamar Tidur Menggunakan Sensor Infrared dan Photodioda Berbasis Arduino Uno. Prototype ini dirancang dapat digunakan dalam penggunaan kehidupan sehari-hari di beberapa ruangan. Perancangan menggunakan kartu yang berfungsi sebagai pemutus tegangan listrik jika penggunaan listriknya tidak dipakai lagi.

Penelitian ini menggunakan metode prototype, meliputi perancangan perangkat keras (hardware), perangkat-lunak (software) dan pengujian sistem secara keseluruhan. Sistem perangkat-keras dirancang secara blok per-blok, mulai dari rangkaian catudaya, rangkaian sensor, rangkaian Arduino Uno.

\subsection{Tujuan Perancangan}

Tujuan Perancangan penelitian ini adalah untuk memperoleh semua hasil yang standar yang telah disesuaikan dalam perangkaian. Perangkaian alat ini 
untuk efisiensi penggunaan listrik khususnya kamar tidur dan ruangan yang lain memiliki penggunaan listrik.

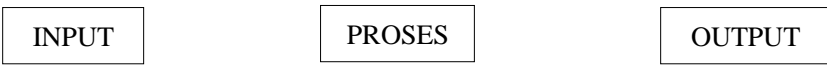

2.2 Rancangan Rangkaian Alat, Bahan dan Peralatan yang Digunakan

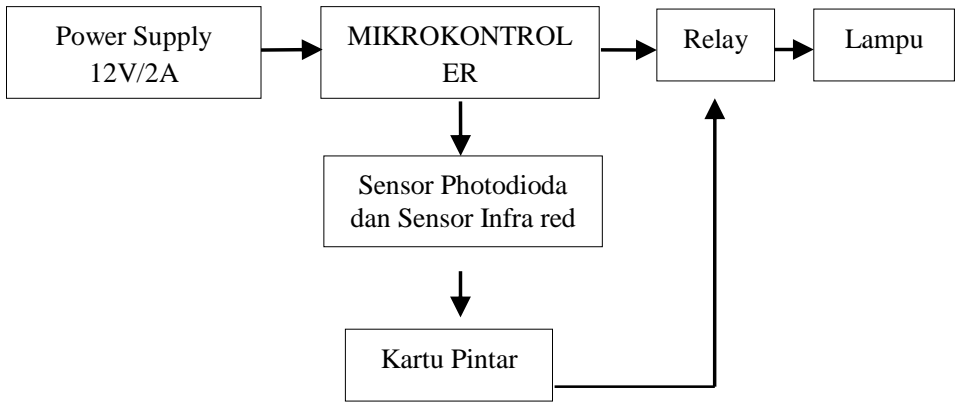

sensor photodioda dan sensor infrared yang peka terhadap cahaya. Cara kerja alat ini adalah apabila kartu mengenai sinar yang dipantulkan oleh sensor photodioda dan sensor infra red maka lampu kamar akan mati.

Gambar 3.1 Blok Diagram Kartu Pintar Kamar Tidur

\subsubsection{Perancangan Perangkat Keras (Hardware)}

Untuk mempermudah perancangan sistem yang digunakan blok diagram sebagai langkah awal pembuatan sistem, dimana blok diagram ini menggambarkan secara umum bagaimana cara kerja sistem dengan keseluruhan.

Dalam perencanaan ini dijelaskan bahwa semua data yang masuk lewat rangkaian input, yang difungsikan sebagai rangkaian input dan data tersebut selanjutnya di proses oleh Arduino Uno dan hasil proses kontrol akan menghidupkan sensor photodioda dan sensor infrared, relay untuk menyambungkan dan memutuskan tegangan dan arus yang masuk sehingga lampu mati. Sistem kerja rangkaian alat ini dapat dilihat pada gambar dibawah ini: 
yang tidak berlubang akan menyebabkan photodioda dan infrared tidak dapat menerima cahaya dari LED. Jumlah dan posisi lubang pada kartu tersebut akan menentukan photodioda dan infrared yang akan menerima cahaya.

Adapun gambar rangkaian kartu pintar kamar tidur dapat dilihat pada gambar berikut:

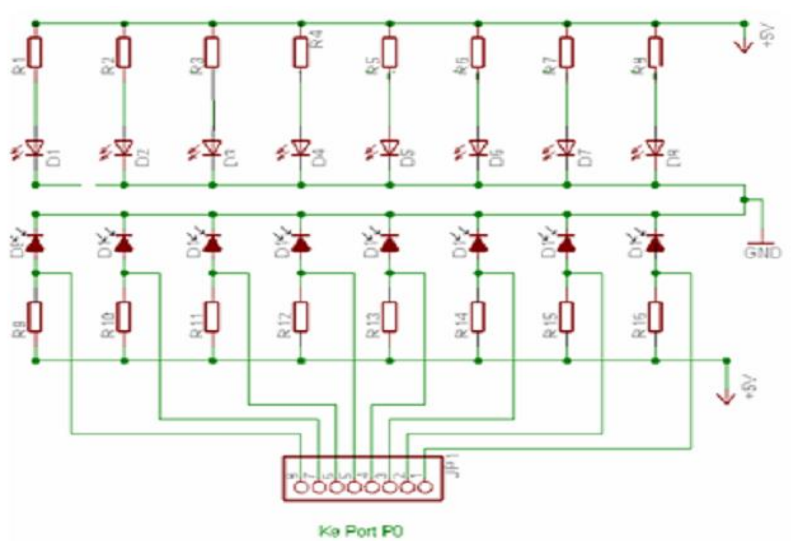

Gambar 3.2 Skematik rangkaian sistem sensor kartu berpassword

\section{$2.4 \quad$ Rancangan Fisik Alat}

Rancangaan fisik prototype rangkaian kamar tidur dengan menggunakan sensor infrared dan sensor photodioda adalah sebagai berikut

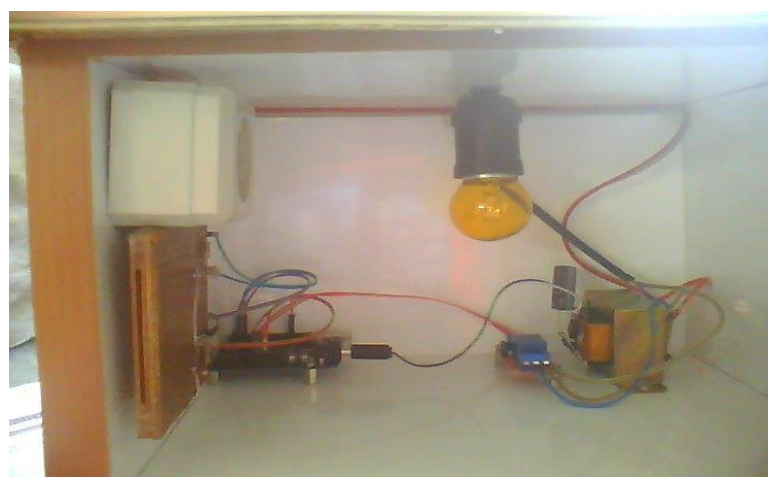

Gambar 3.3 Bentuk Fisik Alat

\subsection{Cara Kerja Sistem}

Cara kerja sistem tersebut adalah sebagai berikut:

1. Arduino Uno berfungsi untuk mengontrol sistem untuk dapat bekerja sesuai dengan yang diharapkan.

2. Catu daya berfungsi untuk memberikan tegangan listrik keseluruh Hardware dari sistem.

3. Power Supply berfungsi untuk menaikkan dan menurunkan tegangan

4. Sensor photodioda dan sensor infrared berfungsi sebagai sensor cahaya

5. Relay berfungsi sebagai penyambung dan pemutus tegangan listrik

6. Kartu bekas berfungsi sebagai penghalang cahaya pada sensor photodioda dan sensor infrared

Jadi cara kerja dari rangkaian tersebut adalah penggunaan kartu pintar yang berfungsi untuk efisiensi penggunaan listrik khusunya kamar tidur, penggunaan kartu pintar yang berfungsi sebagai penghalang cahaya yang masuk mengenai sensor photodioda dan sensor infrared, sehingga relay akan bekerja untuk memutuskan tegangan pada lampu kamar tidur.

III. Hasil dan Pembahasan

Perancangan protype kartu pintar kamartidur ini bertujuan untuk memberikan kemudahan dalam efisiensi pengunaan listirik rumah yang terdiri dari rangkaian Mikrokontroler Arduino Uno sebagai pengontrol sensor photodioda dan sensor infrared, perangkat lunak atau program. Untuk mengendalikan bahwa alat yang dirancang bekerja sesuai dengan yang diharapkan maka dilakukan pengujian perangkat lunak dan perangkat keras. 


\subsection{Pengujian Sistem dan Rangkaian}

Pengujian pada rangkaian sistem yang dilakukan adalah pengujian komponen pendukung dan program sistem dari pembersih debu ini. Pengujian ini dilakukan untuk dapat mengetahui kelebihan dan kekurangan pada protype kartu pintar kamar tidur ini.

\subsection{Analisa Rangkaian}

Beberapa aspek yang perlu dikembangkan dalam pemahaman terhadap sistem merupakan satu kesatuan prosedur inti dari sistem tersebut. Sistem dikatakan lengkap bila dalam mencapai tujuan yang telah ditetapkan terjadi interaksi antara subsistemsubsistem yang ada. Pada sub bab berikut ini akan dijelaskan mengenai analisa perancangan rangkaian secara keseluruhan dan masing-masing yang mendukung tercapainya tujuan pembuatan alat ini.

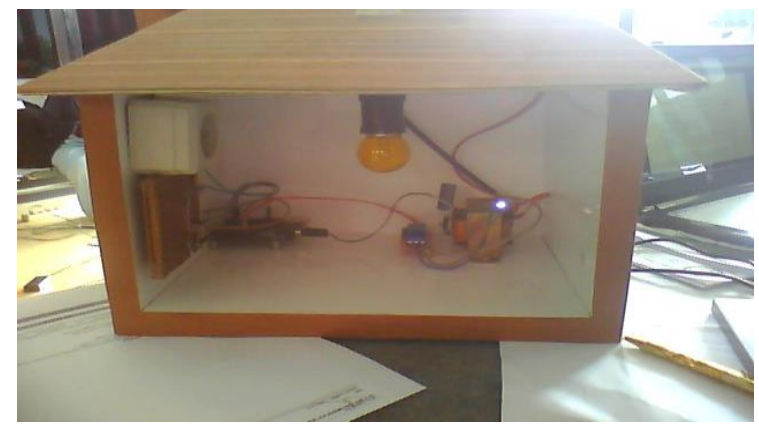

Gambar 4.2 Pengecekan Rangkaian Keseluruhan Bekerja dengan Baik

\section{KESIMPULAN}

Dari hasil penelitian tugas akhir yang telah dilaksanakan, didapat beberapa kesimpulan diantaranya adalah :
1. Perancangan Kartu pintar untuk kamar tidur dengan menggunakan sensor photodioda dan sensor infrared berbasis Arduino Uno telah berhasil dengan baik sesuai prosedur

2. Sistem Kerja dari rangkaian kartu pintar kamar tidur sangat bermanfaat untuk efisiensi penggunaan listik di rumah tangga.

3. Sistem kerja dari sensor photodioda dan sensor infrared sangat baik dalam perangkaian yang berfungsi sebagai sensor cahaya

\section{SARAN}

1. Beberapa saran yang diajukan dalam penelitian kedepannya adalah :

2. 1.Agar penelitian selanjutnya ditambah beberapa sensor

3. 2.Agar penelitian selanjutnya dapat diaplikasikan penggunaan rangkaian pada beberapa ruangan dirumah.

\section{UCAPAN TERIMAKASIH}

Penulis mengucapkan terima kasih kepada perguruan tinggi STMIK Royal Kisaran dan Universitas Asahan dan beberapa pihak-pihak lain yang telah memberi dukungan terhadap penelitian dan penerbitan jurnal ini.

\section{DAFTAR PUSTAKA}

[1] Darmawan Julianto,2010.Perancangan

Otomatisasi Pintu Pada Shelter Busway Dengan

Mikrokontroler AT89S51.Jurusan Teknik 
Elektro.Fakultas Teknologi Industri, Universitas Gunadarma

[2] Heri Andrianto: Hal 89,2013. Pemrograman Mikrokontroler AVR ATMega 16 Menggunakan Bahasa C (Code Vision AVR), informatika,Bandung

[3] Paulus Insap Santosa, 2010.Prototipe Kantin Tanpa Uang Berbasis Kartu Pintar.Jurusan Teknik Elektro dan Teknologi Informasi, Fakultas Teknik, Universitas Gadjah Mada

[4] Tadu Puasandi,2014. Sistem Akses Kontrol Kunci Elektrik Menggunakan Pembacaan e-KTP. Jurusan Teknik Elektro Universitas Brawijaya

[5] Taufiq Dwi Septian : 27-29,2010, Buku Pintar Robotika Bagaimana Merancang \& Membuat Robot Sendiri,CV.ANDIOFFSET.Yogyakarta

[6] Wildian,Riki Saputra,2010, Rancang-Bangun Prototype Sistem Kontrol Pintu Berbasis Mikrokontroler AT89S51 Menggunakan Kartu Ber-password dan Sensor Fotodioda.Jurusan Fisika Universitas Andalas 